\title{
Business Models and the Managerial Sensemaking Process
}

\author{
Syrus M. Islam \\ Department of Accounting \\ Auckland University of Technology \\ New Zealand \\ syrus.islam@aut.ac.nz
}

Suggested citation:

Islam, Syrus M. (2019). "Business models and the managerial sensemaking process", Accounting and Finance (forthcoming), DOI: doi:10.1111/acfi.12459 


\title{
Business Models and the Managerial Sensemaking Process
}

\begin{abstract}
This study examines the managerial sensemaking process around business models. Drawing on fieldwork, this study introduces a model to describe how managerial sensemaking occurs around business model development and use. This study shows that managerial sensemaking around business models occurs through a mutually co-constituted process, a separate yet shared process, or a combination of them resulting from an interplay between sensemaking and sensegiving activities. To facilitate their sensemaking around business models, managers draw on several schemas. Over time, some schemas underlying business models remain unchanged, while others change in varying degrees.
\end{abstract}

Keywords: Business models; Sensemaking processes; Sensegiving; Schemas; Cognition 


\section{Introduction}

The objective of this research is to better understand the managerial sensemaking process underlying the development and use of a firm's business model. A business model refers to a system of interdependent activities (Zott and Amit, 2013), where activities are linked together to develop a coherent story of a firm's operations (Magretta, 2002). Generally, business model development refers to the initial design of a business model, while business model use refers to the subsequent deployment of the business model to communicate and devise courses of action to achieve organisations' visions and objectives (Chesbrough and Rosenbloom, 2002; Zott et al., 2011; Teece, 2010).

The current study examines the following research question: How do managers make sense of the development and use of a firm's business model? The research question is important because business models are fundamental to every organisation (Magretta, 2002). Also, prior research observes that managerial sensemaking is the most important input in the design of business models (Sosna et al., 2010). However, we know little about how managers make sense of business model development and use. Therefore, an investigation into the managerial sensemaking process around business models can contribute to this knowledge gap. Furthermore, recent research suggests that cognitive agenda is one of the most promising research areas for business models (Baden-Fuller and Mangematin, 2013). Schemas or cognitive representations are considered fundamental to sensemaking (Bartunek and Moch, 1987). Therefore, examining the managerial sensemaking process around business models can advance our understandings of how managers' cognitive representations are embedded in their sensemaking processes in related to business model development and use.

The research question is addressed by drawing on data from a field study conducted in an energy and environmental services provider. The analytical framework for this study primarily draws on the sensemaking literature (e.g., Weick, 1995; Maitlis and Christianson, 2014).

This study makes three contributions to the literature. Firstly, it extends the literature discussing the issue of sensemaking in the context of business models (e.g., Magretta, 2002; George and Bock, 2011; Sosna et al., 2010) by introducing a model to describe how managerial sensemaking occurs around business model development and use. The current study appears to be the first comprehensive study that examines the managerial sensemaking process around business models. 
Secondly, this study contributes to our understandings of the essence of business models in organisations (e.g., Magretta, 2002; Teece, 2010) by highlighting a new essence of business models, which is to use them as a guide to (re)design organisations' performance measurement systems. The current study also contributes to prior research by providing insights about how the essence of business models in organisations can change over time, and that business models not only narrate the future (as demonstrated in the existing literature), but also help to narrate the present.

Thirdly, the current study adds to the emerging literature on business models and managerial cognition (e.g., Baden-Fuller and Mangematin, 2013; Martins et al., 2015) by highlighting two broader types of schemas (i.e., cognitive representations) that are fundamental to the development and use of business models. This study further extends this stream of research by demonstrating that schemas underlying business models not only change; they change in varying degrees.

The rest of the paper is structured as follows. The next section provides the theoretical background of this study. Section three details the research methods. Findings are presented in section four. The fifth section discusses the main insights that this article brings to the existing literature. The final section concludes the paper.

\section{Theoretical background}

\subsection{The prior literature}

The prior literature on business models has addressed several important issues. A stream of literature has investigated issues around the design of business models, such as the component of business model design, how to design a business model and the antecedents of business model design (e.g., Zott and Amit, 2010; Casadesus-Masanell and Ricart, 2011). Another stream of literature has examined issues around business model innovation, such as conceptualisation of business model innovation, and requiring capabilities, leadership, and learning mechanisms for successful business model innovation (for a review, see Foss and Saebi, 2017). Other streams of literature have focused on understanding the performance impact of business model adoption and innovation (e.g., Zott and Amit, 2008, 2007; Kastalli and Van Looy, 2013) and the evolution of business models (e.g., Demil and Lecocq, 2010; Sosna et al., 2010). 
However, to date, only a handful of studies have discussed the issue of sensemaking in the context of business model development and use. Chesbrough and Rosenbloom (2002) investigated the effects of the business model on technology commercialisation in Xerox Corporation. The authors noted that the business environment surrounding technology commercialisation is characterised by high complexity and ambiguity. They argued that sensemaking is fundamental in constructing business models in such an environment, since it allows managers to reduce ambiguity and comprehend complex choices faced by them. The authors showed how the technology that made little or no business sense in a traditional business model yielded superior value when introduced in the market with a different business model.

In another study, Magretta (2002) discussed how sensemaking of a business model is relevant to an organisation's success and failure. Among others, the author explained how in its early years, EuroDisney was unsuccessful because its business model did not make sense to its customers, and how the company later became successful after altering some key elements of its business model. Similarly, the author showed how the business model of Priceline Webhouse Club made sense in the airlines ticketing industry, which made the company highly successful, and how the extension of the same business model did not make sense in the groceries and gasoline industries, which led the company out of business.

Sosna et al. (2010) examined how an established organisation innovated its business model. The authors found that the case organisation innovated its business model through trial-anderror learning. The authors also observed that owner-managers' sensemaking was particularly important in the trial-and-error learning leading to business model innovation, since it directly affected their ability to learn.

In another study, George and Bock (2011) conducted a survey of practising managers in early stage technology firms to better understand their conceptualisation of business models and compared that with academic literature. Regarding the issue of sensemaking of business models, the authors discussed how academic researchers and practising managers viewed the importance of narrative sensemaking of business models both within and outside an organisation.

Overall, the above studies offer some useful discussions on the issue of sensemaking around business models from various perspectives. However, these studies provide little insight into how managers actually make sense of the development and use of business models. The current 
study investigates this issue, informed by the analytical framework elaborated in the next section.

\subsection{Analytical framework}

The analysis of this study primarily draws on the literature of sensemaking (Weick, 1995). Because this study seeks to examine the sensemaking process around the development and use of a firm's business model, the concept of sensemaking provides an appropriate lens.

Sensemaking is primarily a conversational and narrative process by which people construct and interpret the social world (Weick, 1995; Gephart, 1993). As part of sensemaking, people engage in gossip and negotiations, exchange stories and past experiences, and seek information to infer and give meaning (Maitlis and Christianson, 2014).

In organisations, sensemaking occurs when members confront somehow surprising, complex, or confusing events and issues (Weick and Roberts, 1993; Gioia and Thomas, 1996). Organisational sensemaking is collective in nature, where "organization members interpret their environment in and through interactions with others, constructing accounts that allow them to comprehend the world and act collectively" (Maitlis, 2005, p. 21). Here, it should be noted that collective sensemaking does not necessarily indicate a completely agreed-upon understanding; rather, understandings that are close enough to mobilise coordinated actions in firms (Maitlis and Christianson, 2014; Donnellon et al., 1986).

Collective sensemaking in organisations can occur through a mutually co-constituted process. Here, organisational members jointly engage with the focal issue and build their understanding of it together. For example, in the study by Stigliani and Ravasi (2012) of an international design consultancy firm, designers and clients jointly developed a common understanding of the goal and attributes of the design project. As part of collective sensemaking, they together engaged with the issue and exchanged and integrated their provisional understandings of the project goal and attributes in multiple iterations until they agreed on consensual interpretations.

Collective sensemaking in organisations can also occur through a separate yet shared process. Here, sensemaking first occurs within the head of a particular member, who later influences others' sensemaking. For example, in the study by Gioia and Chittipeddi (1991) of the initiation of strategic change in a large public university, the newly appointed president first developed a new vision of making the university a "Top 10" public university. In relation to this new vision, he proposed a number of strategic change projects in which he had a strong personal 
interest. He then held frequent meetings with key stakeholders to explain the nature of the new vision, the values underlying it, and the possible outcomes of the proposed strategic change projects. Thus, the president influenced important stakeholders to agree on the proposed strategic change projects.

One important thing to note in the studies by Stigliani and Ravasi (2012) and Gioia and Chittipeddi (1991) is that as part of collective sensemaking, organisational members influenced the sensemaking of others. The process of influencing others' sensemaking is known as sensegiving, which is considered an integral part of collective sensemaking processes (Maitlis and Lawrence, 2007). In fact, in a collective sensemaking process, sensemaking and sensegiving are considered two complementary and reciprocal processes (Rouleau, 2005).

The current study's analysis also draws on another important concept - schemas, which are central to organisational sensemaking (Bartunek, 1984; Balogun and Johnson, 2004). Schemas serve as a fundamental assumption about "why events happen as they do and how people are to act in different situations" (Bartunek, 1984, p. 355). In its broadest form, a schema is a cluster of thematically related knowledge, which provides individuals with a cognitive basis for interpreting and responding to events and issues (Poole et al., 1989).

Organisational schemas are the frame of references shared among organisational members, which provides a common orientation towards events (Bartunek and Moch, 1987). Organisational members routinely draw on schemas to interpret, understand, and respond to organisational events and issues (Rouleau, 2005). For example, in the study by Balogun and Johnson (2004) of strategic change in a utility firm, middle managers drew on several schemas (e.g., organisation as hierarchy, common purpose, organisation as multidivisional, interdivisional relationship, change process, etc.) to comprehend the sudden imposition of a new modular organisational form. However, not all schemas were developed at the same time. Rather, different schemas were developed at different times depending on the specific situation. Over time, some of the initially developed schemas changed, while others remained the same. Through the above sensemaking lens, the current study investigates how managers make sense of the development and use of business models. The next section details the research methods for this study.

\section{Research methods}


This paper builds on a field study conducted in a single organisation between October 2014 and September 2015. Because this study aimed at understanding the actual sensemaking process underlying the development and use of a firm's business model, a field study approach was required.

ElectricNZ, ${ }^{1}$ the case company, is a New Zealand-based energy and environmental services provider. The company generates annual revenues of more than NZ\$100 million and employs more than 500 employees. The company has five departments: Finance \& Systems, Capability \& Risks, Environmental Services, Asset Management, and Energy \& Communications.

ElectricNZ delivers a wide range of energy services, including electricity generation, transmission, and distribution to industrial and residential electricity users, electricity metering, and infrastructure services to fibre optic asset management. The company also provides environmental services, including solid waste services (e.g., rubbish and recycling collection) and greenspace services (e.g., maintenance of public parks, reserves, and gardens).

\subsection{Data collection}

Data were collected from three main sources: interviews, non-participant observations in managerial meetings, and company documents. In qualitative field research, the researcher aims to "identify and include those actors and sources that can best inform the focus of their inquiries and produce the richest account of the phenomenon under investigation" (Parker and Northcott, 2016, p. 1116). In line with this, this study sought to interview company members who were closely involved in the company's business model development and use initiatives. The company's top management team comprised of five senior managers: the chief executive officer (CEO); the chief financial officer (CFO); and the general managers (GMs) of the Capability \& Risks (C\&R), Asset Management (AM), and Energy \& Communications (E\&C) departments. In addition to the top management team, the business improvement and risk manager (BIRM) and the human resources manager (HRM) were heavily involved in the company's business model development and use, and were frequently invited to several toplevel meetings. A total of 17 semi-structured interviews were conducted with all seven of these senior managers, which lasted one hour on average (see Table 1). The CFO, the GM, C\&R, and the BIRM were interviewed more times than others because they had more involvement in and knowledge of issues around the company's business model.

\footnotetext{
${ }^{1}$ The original name is disguised.
} 
The interviews were conducted in two rounds. The first round, which was conducted in the last quarter of 2014, was wide in its scope in terms of the topics covered and people interviewed. The first-round interviews covered the following main topics: company's overall business conditions and its strategic context, the context of developing the existing business model, people involved in the development of the business model, and how various parts of the business model were initially developed. The second-round interviews, conducted between quarter one and quarter three in 2015, focused more on understanding sensemaking activities regarding the ongoing use of the company's business model. The following main topics were covered in the second-round interviews: main reasons for the ongoing use of the business model as a whole, why various parts of the business model had or had not changed, and new business conditions that had prompted discussion on and around the business model in the company.

The second data source was non-participant observations in managerial meetings on and around the business model. A total of nine such meetings were observed. This was possible because the researcher spent two to three days per week on site in the company during the research period. Extensive notes were taken during all interviews and observations, which were transcribed afterwards as soon as possible. Following the interviews and observations, the researcher had the opportunity to clarify any topics with relevant company members. These clarifications are also included in the transcripts.

In addition to interviews and observations, a total of 15 major company documents (e.g., strategy, business model, performance measurement, etc.) were reviewed. This provided a deeper understanding of the company's overall business condition, strategic context, and business model.

\subsection{Data analyses}

Data were analysed in several stages. First, data were categorised into two broader themes: making sense of the initial development of the business model, and making sense of the subsequent use of the business model.

Second, data were coded for "schemas" in relation to both business model development and business model use. While coding for schemas, particular attention was given to identifying the cluster of thematically related knowledge upon which senior managers drew to interpret 
issues around business model development and use. Furthermore, coded schemas were categorised into two ways: parent and child. The overarching schemas that informed the development and use of the overall business model were categorised as parent schemas. In contrast, the sub-schemas that informed the development and use of various parts of the business model were categorised as child schemas.

Third, data were coded for "sources of schemas". Two broader sources of schemas were identified: internal (e.g., company's vision, strategic direction) and external (e.g., market information, customer company documents).

\section{Findings and analysis}

\subsection{Sensemaking while developing the business model}

The company's current business model (see Figure 1) was developed before October 2014. This section describes how senior managers made sense of the initial development of their business model. $^{2}$

\section{[Insert Figure 1 here]}

\subsubsection{Making sense of the development of the overall business model}

While developing the initial business model, senior managers first stressed the understanding of the overarching rationality of developing the business model as a whole. As the BIRM noted: "The very first question that we asked ourselves was: What is the main goal of developing a [business] model?" Similarly, the CFO echoed: "Our first task was to agree on: Why are we building our model?"

The overarching schema, which this paper calls the parent schema, upon which senior managers drew to interpret the development of the company's overall business model appeared to be the "clear depiction of vision" (see Table 2). Senior managers understood the business model as a vehicle through which organisational members could better comprehend and reflect on where the company would want to be in the future (i.e., vision) and how it would reach that point:

\footnotetext{
${ }^{2}$ As this research engagement started after the development of the company's current business model, the researcher was not present during the development of the company's business model. Therefore, the empirics presented in section 4.1 are mostly based on the senior managers' recollection of the events.
} 
To us, our [business] model is a roadmap to our future. (CEO)

It is very important that our members can clearly visualise what is our vision. It is also important that we understand well what it would take us to go there [i.e., vision]. And, our [business] model serves this agenda. (BIRM)

\subsubsection{Making sense of the development of parts of the business model}

Once senior managers agreed on the overarching rationality of developing their business model, they focused on developing various parts of the business model. To do this, senior managers drew on several sub-schemas, which this paper calls child schemas.

To illustrate how senior managers made sense of developing various parts of the business model, this study presents empirics in relation to three selective parts (see Figure 1). These parts are chosen because of the richness of data available regarding them. However, it should be noted that the findings regarding these selective parts of the business model adequately represent findings regarding other parts of the business model.

\section{[Insert Table 2 here]}

\subsubsection{Part A of the business model}

While developing this part of the business model (see Figure 1), senior managers appeared to draw on the "gain efficiency" schema (see Table 2). One of the strategic priorities of the company was cost reduction through improved operating efficiency. To reduce costs, senior managers intended to focus on four key activities (see Figure 1), which were centred on the gain efficiency schema:

Greater cost control through improved operating efficiency was a key strategic priority. We discussed identifying ways to gain efficiency within our current operations. Then we selected four key activities, such as streamlining our current processes, minimising our waste, avoiding any work and role duplication, and consolidating our different systems and applications. (GM, C\&R)

We agreed that we have a lot of room to achieve efficiency. So, we identified four major areas of our operations that we should focus on for [achieving efficiency and] some significant cost savings. (BIRM)

\subsubsection{Part B of the business model}


While developing part B of the business model (see Figure 1), senior managers seemed to draw on the "follow asset management plan" schema (see Table 2). ElectricNZ would provide asset management services to Beta Energy under a long-term (usually 10 years) asset management plan. This plan would specify the capital and maintenance programmes needed to be performed and the required network quality targets to be met by ElectricNZ. That is, the requirements of the asset management plan guided senior managers to choose activities to generate Beta Energy electricity revenue:

We are the asset manager of Beta Energy, which is our single biggest customer. We provide them service through a 10 -year asset management plan. It is very important for us that we strictly follow the asset management plan. (GM, AM)

Our asset management plan tells us what capital and maintenance work we need to carry out for Beta [Energy], and what standard of network quality performance we need to maintain. If we fail to meet them [i.e., the asset management plan], our revenue could drop significantly. (CFO)

\subsubsection{Part $C$ of the business model}

While developing this part of the business model (see Figure 1), senior managers appeared to draw on the "request-for-proposals from clients" schema (see Table 2). In several interviews, request-for-proposals (RFPs) were the recurring theme, which guided senior managers to choose activities to win contracts from new customers in the third party electricity services sector:

To win [contracts from] new customers, we need to pay close attention to what they [i.e., customer companies] are asking for in their request-for-proposals. So, if you look [at] a typical request-for-proposal, they ask for [a] few things. First, whether the provider has the ability to perform the job. [...] One way of demonstrating qualification is, yes, the company has done it before. If no [i.e., the company had not done similar jobs before], then it is almost impossible to demonstrate that they can actually provide service according to specifications. And, second, how much is the price? [...] Finally, we need to submit a very high quality tender, which should meet every single specification mentioned in a request-for-proposal. (BIRM) 
In our industry, if you wait till [the] formal RFPs circulation, you are less likely to win them. Having good relationships with your customers is an extra plus. If you have that [good relationships with customers], you will know upfront about any upcoming tender opportunity. You can also know in advance what are the key things you need to do to win that potential tender. (GM, E\&C)

It is the RFP that guides us in what we must need to do to win new clients. (GM, $\mathrm{C} \& \mathrm{R})$

Overall, at ElectricNZ, while developing the initial business model, senior managers first drew on parent schemas, which gave meaning to the overarching rationality of the development of the business model as a whole. The parent schema was clear depiction of vision, and the source of this schema was the company's vision (i.e., an internal source) (see Table 2). Then senior managers drew on several child schemas to inform the development of various parts of the business model. Regarding the development of part A of the business model, the schema was gain efficiency, and its source was a strategic priority of the company (i.e., an internal source) (see Table 2). While developing part B of the business model, the schema was follow asset management plan, and the source of this schema was the company's asset management plan document (i.e., an internal source) (see Table 2). Furthermore, request-for-proposals from clients was the schema underlying the development of part $\mathrm{C}$ of the business model, and the source of this schema was the RFP documents provided by customer companies (i.e., an external source) (see Table 2).

\subsection{Sensemaking while using the business model}

This section describes how senior managers made sense of the ongoing use of their business model following its initial development.

\subsubsection{Making sense of the use of the overall business model}

As noted earlier, while developing the initial business model, senior managers drew on clear depiction of vision as the parent schema. In the post-development period of the business model, this old parent schema still informed the overarching rationality of the continuation of the company's business model (see Table 2).

However, in recent times, a new parent schema - "better performance measurement" emerged. That is, senior managers found another overarching rationality of the continued use of the overall business model, which was to use activities in the business model as a guide to 
redesign the company's existing performance measurement system. This new overarching rationality of the business model was first conceptualised by the BIRM, as he noted:

Well, our operating model will continue to narrate our future [i.e., vision], but at the same time we need to clearly portray our present. [...] I mean, currently we have a [performance] measurement system, but I suspect it is not well aligned with our [business] model. I think a better idea would be to use activities in the model as a guide to develop new measures or align our current measures. In that case, our model could not only guide our future, but also our current performance. (BIRM)

Upon conceptualising this new overarching rationality of the business model, the BIRM separately held several personal discussions with his colleagues to explain it. That is, the BIRM had adopted a sensegiving mode to influence the sensemaking of his colleagues. As he continued: "I have personally discussed this [i.e., the issue of the new overarching rationality of the business model] with some of my colleagues, and they are okay with this". The sensegiving of the BIRM regarding the use of the business model to align the company's performance measurement system was also confirmed by another senior manager:

Currently, we are seriously thinking of how our operating model could inform our measurement system. Actually, the BIRM came up with this idea. It looked promising to me, although it means now we need to do more work around our [business] model and [performance] measurement system [laughing]! I guess others are also happy about it. (CFO)

After a few weeks, the company started a new initiative to redesign its existing performance measurement system in alignment with its business model. The BIRM and the CFO had had the overall responsibility to administer this new initiative.

Overall, sensemaking around the new overarching rationality of the company's business model took place through a separate yet shared process. That is, the idea of the new overarching rationality of the business model first made sense to the BIRM. He then separately persuaded other senior managers through personal discussions to agree on his idea. The BIRM appeared to be successful in persuading other senior managers, since the company started a coordinated action to redesign its performance measurement system in line with its business model. Furthermore, over time, the initially drawn on parent schema underlying the business model co-existed with new parent schema (i.e., schema addition, see Table 2). 


\subsubsection{Making sense of the use of parts of the business model}

To illustrate how senior managers made sense of the use of various parts of the business model, the following section presents empirics in relation to the same three selective parts as presented in section 4.1.2.

\subsubsection{Part A of the business model}

Part A of the business model was initially developed drawing on the gain efficiency schema. Since the development of this part of the business model, the company focused on four major areas of its operations to gain efficiency (see Figure 1). Although the company was successful in gaining operating efficiency, from mid-2015, senior managers did not see any major costsaving opportunities through efficiency gain. As a result, they were thinking about revising this part of the business model. The company then organised a meeting where senior managers jointly exchanged each other's interpretation of the issue. However, they could not decide whether the efficiency focus would be completely abandoned from the business model or whether they would focus on identifying new ways of gaining efficiency. Rather, senior managers decided to discuss this issue further in the next review meeting and try to finalise a decision. The following episode from the meeting illustrates this point:

CFO: We have reaped most of the potential of cost reductions through productivity gain. So, in future, significant cost reduction opportunities [through efficiency gain] are almost nil.

HRM: I also don't see much scope to gain efficiency from our operations. Probably, we should stop focusing on this.

GM, AM: Well, I have different views. I think efficiency gain is important and we should find new ways [for gaining efficiency].

GM, C\&R: We need to think more about it.

A few days after the above meeting, the GM, C\&R came up with the idea that although there was not much scope to gain operating efficiency in the future, the company should not abandon the focus on efficiency in its business model. This was because abandoning efficiency focus could encourage inefficiency in the company, which, in turn, could incur extra costs. He understood that the company's business model should still focus on efficiency, but now the 
main motivation would be to maintain the current level of efficiency. The GM, C\&R mentioned this as follows:

Well, in our last meeting, we could not decide what to do with our cost reduction and efficiency issue. Later, I pondered over this issue. My take is that if we don't focus on efficiency, then it would not give a good signal to our employees. It could encourage inefficiency [in the company]. I believe we should not change our [this part of business] model. We should still focus on efficiency, but the main focus would now be to maintain the current level of efficiency.

Then, the GM, C\&R tried to convince other senior managers through separate discussions about the idea of efficiency maintenance and not revising this part of the business model. As he continued:

In the last few days, I had a separate chat about this with four [senior managers], and three of them bought it. One colleague didn't like [it] much. You know, some will buy it, and some won't. And, this is how it is. Let's see what we decide in our next meeting. [GM, C\&R]

However, the company could not decide any specific courses of action until the next business model meeting, where senior managers further jointly engaged with the issue. In this meeting, the GM, C\&R took the lead, and the majority of the senior managers who attended supported him. Accordingly, the company did not revise this part of its business model. Rather, it continued to focus on the existing four key activities underlying this part of the business model to maintain the current level of efficiency. The following episode from that meeting illustrates this:

GM, C\&R: I strongly believe that we should not completely abandon [the] efficiency part from our operating model. We should focus on efficiency but in a different way. I mean, as opportunities to gain operating efficiency are less, we should maintain our current efficiency level. Otherwise, I am worried that we might lose the efficiency that we have gained in the past.

BIRM: I second the idea.

HRM: Well, I am not a big fan of efficiency, but it might be just me! 
GM, AM: I agree with the GM, C\&R. I think maintaining efficiency should be a priority now.

In summary, sensemaking around the issue of lack of opportunities to gain efficiency and its potential impact on the design of the business model took place through a combination of mutually co-constituted and separate yet shared processes. Senior managers first jointly engaged with the new situation to develop a common understanding of the possible revision in the business model. This was a mutually co-constituted sensemaking process. However, in this first joint engagement session, they could not mutually agree on whether the efficiency focus would be totally abandoned from the business model or whether they would focus on identifying new ways of gaining efficiency. A few days later, the GM, C\&R first conceived the idea of focusing on maintaining the current level of efficiency, rather than completely abandoning the efficiency focus in the business model. He then tried to persuade other senior managers through separate discussions to agree with his idea. This was a separate yet shared sensemaking process. However, the company could not decide any specific course of action until the next business model meeting, where senior managers again jointly engaged with the issue, then mutually agreed to focus on efficiency maintenance in the business model. This was again a mutually co-constituted sensemaking process. The findings also show that in light of the new situation, the old schema went through incremental fine-tuning - i.e., from "gain efficiency" to "maintain efficiency" (i.e., schema refinement, see Table 2). This newly refined schema, maintain efficiency, gave meaning to continue to focus on the existing four key activities underlying this part of the business model.

\subsubsection{Part B of the business model}

As mentioned previously, the schema underlying the initial development of this part of the business model was follow asset management plan. In the post-development period of the business model, senior managers still drew on the same schema to interpret the continued use of this part of the business model. This can be seen from the following meeting episode:

CFO: I believe we should continue to focus on what we are currently doing. I mean, delivering on the requirements of our single biggest customer; to achieve its quality targets and capital projects as outlined in the asset management plan. By doing so, we will maximise sustainable revenue. 
GM, E\&C: I do think so. Meeting Beta Energy's requirement [i.e., asset management plan] is the most attractive source of growth for us. We should particularly focus on boosting our asset management planning and delivery.

BIRM: I see that revenue from Beta Energy currently contributes around 53\% of our total revenues. We should aim not only to deliver our asset management plan in full, but also to raise asset management professionalism to the next level within three years.

HRM: Guys, everything looks good to me.

The above episode indicates that sensemaking around this part of the business model took place through a mutually co-constituted process. That is, senior managers jointly exchanged their understandings of this part of the business model, then mutually agreed to continue to focus on delivering the asset management plan to improve Beta Energy electricity revenue. Furthermore, the initially drawn on schema underlying this part of the business model remained the same over time (i.e., schema sustainment, see Table 2).

\subsubsection{Part $C$ of the business model}

As noted earlier, to initially develop this part of the business model, senior managers drew on the request-for-proposals from clients schema. From early 2015, the company experienced slow market growth in the electricity services sector. In light of this changing market condition, the company called for a meeting to jointly engage with the issue. In the meeting, senior managers jointly exchanged each other's interpretation of slow market growth and how the activities underlying the business model might need to be changed in response to this changing market situation. Finally, they mutually agreed to continue to focus on the existing four activities underlying this part of the business model to win contracts from new customers in the electricity services sector. That is, sensemaking around the issue of slow market growth and its potential impact on the design of the company's business model took place through a mutually co-constituted process. The following episode from the meeting illustrates this point:

GM, E\&C: We are experiencing slow market growth in the electricity market. It means that winning new contracts is getting tough and will be tougher in future. Perhaps it's time to rethink how we gonna win new contracts. 
GM, AM: I don't know but am wondering that in this slow growth time whether we need to make a major change in the activities that we are currently focusing on [to win new contracts].

HRM: Should we focus more on activities like strong branding? Also, during this time [i.e., slow growth market], I think competitive pricing is not the one that we should follow. Rather, we should really focus on temporary price discounts.

GM, C\&R: Hold on, hold on. We need to remind ourselves that we don't judge the situation too quickly. My 25 years plus experience says that we should observe the situation closely, and we should not act too hastily. My experience says that as things unfold, we would better understand the market, and then perhaps we could take a more informed decision.

GM, E\&C: I think you (the GM, C\&R) are right. We should wait and see how the market moves. Also, I believe only a better performance in them [i.e., four activities underlying this part of the business model] can help us to bag new contracts.

GM, AM: I am not sure how much I agree, but I would be interested in 'wait and see' approach!

The above episode also shows that unlike the initial development phase of this part of the business model, the request-for-proposals from clients schema was absent in the current discussion. Rather, the current discussion was centred on the "slow market growth" schema. That is, the request-for-proposals from clients schema was replaced by slow market growth schema upon which senior managers drew to interpret this part of the business model (i.e., schema replacement, see Table 2).

\section{Discussions and contributions}

This study has examined how managers make sense of the development and use of business models. The current study contributes to the literature in three ways. Firstly, this study contributes to the prior research that discusses the issue of sensemaking in the context of business model development and use (e.g., Magretta, 2002; George and Bock, 2011; Sosna et 
$a l ., 2010)$. This study agrees with the prior research, suggesting that managerial sensemaking plays an important role in the design of business models. The current study extends this stream of research by introducing a model to describe how managerial sensemaking occurs around business model development and use (see Figure 2).

\section{[Insert Figure 2 here]}

The findings of this study suggest that managerial sensemaking around business models can occur through a mutually co-constituted process, a separate yet shared process, or a combination of them resulting from an interplay between sensemaking and sensegiving activities. At ElectricNZ (the case company), at times, managers made sense of a certain issue around the business model through a mutually co-constituted process, where they jointly engaged with the focal issue and mutually agreed on a course of action around the business model. For example, regarding part $\mathrm{C}$ of the business model in its post-development period (see section 4.2.2.3), managers jointly engaged with the issue of changing market conditions and its potential impact on the design of the business model, simultaneously exchanged each other's interpretation of the issue, then mutually agreed to continue to focus on the existing activities underlying this part of the business model to win contracts from new customers.

At other times, managers made sense of a certain issue around the business model through a separate yet shared process. Here, an individual manager first made sense of a certain issue around the business model. He then separately influenced other managers to agree on his view of the issue. For example, in the post-development period of the business model (see section 4.2.1), an individual manager first conceived the idea of a new overarching rationality of the business model in the company, which was to use the business model as a guide to (re)design the company's existing performance measurement system. Then, that manager separately persuaded other managers through personal discussions to agree on the new overarching rationality of the business model.

At other times, managers made sense of a certain issue around the business model through a combination of mutually co-constituted and separate yet shared processes. For example, regarding part $\mathrm{A}$ of the business model in its post-development period (see section 4.2.2.1), the first sensemaking process was a mutually co-constituted one, where managers jointly engaged with and simultaneously exchanged their interpretation of the issue of lack of opportunities to gain efficiency and its potential impact on the design of the business model. However, they could not reach a mutual agreement about the next course of action around the business model. 
Then, the second sensemaking process was a separate yet shared one, where an individual manager first conceived the idea of focusing on efficiency maintenance in the business model. He then tried to persuade some other managers through separate discussions to agree on his idea. However, the company still could not decide any specific course of action in this regard. Then, the third and final sensemaking process was again a mutually co-constituted one, where managers further jointly engaged with the issue, then mutually agreed to continue to focus on existing activities underlying the business model to maintain the current efficiency level.

Furthermore, this study shows that managers make sense of issues around business models by drawing on schemas. At ElectricNZ, to facilitate their sensemaking around business models, managers drew on several schemas, which informed the development and use of the overall business model and its various parts. Some of these schemas were developed from internal sources, such as the company's vision and strategic priorities, while others were developed from external sources, such as request-for-proposal documents from clients and new market information. This indicates that the sources of schemas underlying business models can be internal and/or external to organisations. Overall, the model developed in this paper contributes to the prior business model research by advancing our understandings of how managers make sense of issues around business model development and use.

Secondly, the current study sheds light on the essence of business models in organisations. The prior research (e.g., Magretta, 2002; Teece, 2010) mainly suggests that the essence of business models in organisations is in depicting how organisations operate towards achieving their visions and objectives. The findings of this study also support this. At ElectricNZ, the business model was considered a tool to visualise how the organisation would achieve its vision. However, the current study extends the prior research by highlighting another essence of business models in organisations. At ElectricNZ, another essence of the business model was to use activities in the business model as a guide to develop new performance measures and/or align the existing performance measures.

The findings of this study also indicate that the essence of business models in organisations can change over time. At ElectricNZ, while developing the initial business model, the underlying essence was to depict how the company's vision would be achieved. However, in the post-development period of the business model, another essence of the business model emerged, which was to use it as a guide to design the company's performance measurement system. This also suggests that business models not only narrate the future (as demonstrated in 
the existing literature), but also help to narrate the present. Business models narrate the future by depicting how the vision would be achieved. Business models help to narrate the present through guiding the design of the performance measurement systems, which measures current organisational performance.

Thirdly, the current study also contributes to the emerging literature on business models and managerial cognition. This study agrees with the prior research (e.g., Baden-Fuller and Mangematin, 2013; Doz and Kosonen, 2010), suggesting that business models are the reflection of managerial schemas (i.e., cognitive representations). At the same time, the current study extends the prior research by offering two broader types of schemas, which seem to be fundamental to the development and use of business models. The first type is parent schemas upon which managers draw on to interpret the overarching rationality of developing and using the business models as a whole. The second type is child schemas, based on which managers comprehend issues around the development and use of various parts of the business model.

Furthermore, the prior research suggests that schemas underlying business models are "particularly inertial and cannot be easily modified" (Martins et al., 2015, p. 105). The findings of this study also support this by demonstrating that some schemas underlying the case company's business model remained unchanged over time (i.e., schema sustainment). However, the current study complements the prior research by demonstrating various changes that schemas underlying business models can go through. At ElectricNZ, over time, some schemas underlying the company's business model went through incremental fine-tuning (i.e., schema refinement), some were replaced by a new schema (i.e., schema replacement), and some co-existed with a new schema (i.e., schema addition). This suggests that schemas underlying business models can not only change; the degree of their change can also vary (e.g., refinement, replacement, addition).

\section{Conclusion}

Drawing on fieldwork, this study examines how managers make sense of business model development and use. The current study shows that managerial sensemaking around business model development and use occurs through a mutually co-constituted process, a separate yet shared process, or a combination of them. To facilitate their sensemaking around business models, managers draw on several schemas. Some schemas inform the overarching rationality 
of developing and using the overall business model, while others inform the development and use of various parts of the business model.

This study has contributed to the literature in three ways. Firstly, the current study extends the literature that discusses the issue of sensemaking around business models by introducing a model to describe the managerial sensemaking process around business model development and use. Secondly, this study adds to the prior business model research by highlighting a new essence of business models in organisations and providing an insight that business models not only narrate the future, but also help to narrate the present. Thirdly, the current study complements the emerging literature on business models and managerial cognition by highlighting two broader types of schemas that are fundamental to business model development and use and offering an insight that schemas underlying business models change in varying degrees.

The current study offers a number of future research avenues. Firstly, future researchers could apply the model developed in this study to further examine the sensemaking process underlying the development and use of business models in other organisational settings. This could lead to further development of the model presented in this paper. Secondly, the current study has investigated the top-level managers' sensemaking process around a business model. However, while implementing a business model throughout an organisation, it must make sense to downthe-level managers (e.g., middle managers, operational managers). Future research could investigate how middle/operational managers make sense of a business model, and whether and to what extent their sensemaking processes differ from that of top-level managers. Furthermore, if the sensemaking process around a business model differs between top-level and middle/operational managers, how does an organisation reconcile this difference and move forward? 


\section{References}

Baden-Fuller, C., and V. Mangematin, 2013, Business models: A challenging agenda, Strategic Organization 11, 418-427.

Balogun, J., and G. Johnson, 2004, Organizational restructuring and middle manager sensemaking, Academy of Management Journal 47, 523-549.

Bartunek, J. M., 1984, Changing interpretive schemes and organizational restructuring: The example of a religious order, Administrative Science Quarterly, 355-372.

Bartunek, J. M., and M. K. Moch, 1987, First-order, second-order, and third-order change and organization development interventions: A cognitive approach, The Journal of Applied Behavioral Science 23, 483-500.

Casadesus-Masanell, R., and J. E. Ricart, 2011, How to design a winning business model, Harvard Business Review 89, 100-107.

Chesbrough, H., and R. S. Rosenbloom, 2002, The role of the business model in capturing value from innovation: Evidence from Xerox Corporation's technology spin-off companies, Industrial \& Corporate Change 11, 529-555.

Demil, B., and X. Lecocq, 2010, Business model evolution: In search of dynamic consistency, Long Range Planning 43, 227-246.

Donnellon, A., B. Gray, and M. G. Bougon, 1986, Communication, meaning, and organized action, Administrative Science Quarterly, 43-55.

Doz, Y. L., and M. Kosonen, 2010, Embedding strategic agility: A leadership agenda for accelerating business model renewal, Long Range Planning 43, 370-382.

Foss, N. J., and T. Saebi, 2017, Fifteen years of research on business model innovation: How far have we come, and where should we go?, Journal of Management 43, 200-227.

George, G., and A. J. Bock, 2011, The business model in practice and its implications for entrepreneurship research, Entrepreneurship Theory and Practice 35, 83-111. 
Gephart, R. P., 1993, The textual approach: Risk and blame in disaster sensemaking, Academy of Management Journal 36, 1465-1514.

Gioia, D. A., and K. Chittipeddi, 1991, Sensemaking and sensegiving in strategic change initiation, Strategic Management Journal 12, 433-448.

Gioia, D. A., and J. B. Thomas, 1996, Identity, image, and issue interpretation: Sensemaking during strategic change in academia, Administrative Science Quarterly, 370-403.

Kastalli, I. V., and B. Van Looy, 2013, Servitization: Disentangling the impact of service business model innovation on manufacturing firm performance, Journal of Operations Management 31, 169-180.

Magretta, J., 2002, Why business models matter, Harvard Business Review 80, 86-92.

Maitlis, S., 2005, The social processes of organizational sensemaking, Academy of Management Journal 48, 21-49.

Maitlis, S., and M. Christianson, 2014, Sensemaking in organizations: Taking stock and moving forward, Academy of Management Annals 8, 57-125.

Maitlis, S., and T. B. Lawrence, 2007, Triggers and enablers of sensegiving in organizations, Academy of Management Journal 50, 57-84.

Martins, L. L., V. P. Rindova, and B. E. Greenbaum, 2015, Unlocking the Hidden Value of Concepts: A Cognitive Approach to Business Model Innovation, Strategic Entrepreneurship Journal 9, 99-117.

Parker, L. D., and D. Northcott, 2016, Qualitative generalising in accounting research: concepts and strategies, Accounting, Auditing \& Accountability Journal 29, 1100-1131.

Poole, P. P., D. A. Gioia, and B. Gray, 1989, Influence modes, schema change, and organizational transformation, The Journal of Applied Behavioral Science 25, 271-289. 
Rouleau, L., 2005, Micro-practices of strategic sensemaking and sensegiving: How middle managers interpret and sell change every day, Journal of Management Studies 42, $1413-1441$.

Sosna, M., R. N. Trevinyo-Rodríguez, and S. R. Velamuri, 2010, Business model innovation through trial-and-error learning: The Naturhouse case, Long Range Planning 43, 383407.

Stigliani, I., and D. Ravasi, 2012, Organizing thoughts and connecting brains: Material practices and the transition from individual to group-level prospective sensemaking, Academy of Management Journal 55, 1232-1259.

Teece, D. J., 2010, Business models, business strategy and innovation, Long Range Planning 43, 172-194.

Weick, K. E., 1995, Sensemaking in Organizations (Sage Publications, Thousand Oaks).

Weick, K. E., and K. H. Roberts, 1993, Collective mind in organizations: Heedful interrelating on flight decks, Administrative Science Quarterly, 357-381.

Zott, C., and R. Amit, 2007, Business model design and the performance of entrepreneurial firms, Organization Science 18, 181-199.

— 2008 , The fit between product market strategy and business model: Implications for firm performance, Strategic Management Journal 29, 1-26.

_ 2010, Business model design: An activity system perspective, Long Range Planning $43,216-226$.

_ , 2013, The business model: A theoretically anchored robust construct for strategic analysis, Strategic Organization 11, 403-411.

Zott, C., R. Amit, and L. Massa, 2011, The business model: Recent developments and future research, Journal of Management 37, 1019-1042. 
Table 1: Empirical evidence collected

\begin{tabular}{lcc}
\hline Data & \multicolumn{2}{c}{ Quantity } \\
\hline Interviews & First round & Second round \\
& $(\mathrm{Q} 42014)$ & (Q1-Q3 2015) \\
Chief executive officer & 1 & - \\
Chief financial officer & 2 & 1 \\
General manager, Capability \& Risks & 2 & 2 \\
General manager, Energy \& Communications & 1 & - \\
General manager, Asset Management & 1 & 1 \\
Business improvement and risk manager & 2 & 2 \\
Human resources manager & 1 & Total number \\
& & 9 \\
Non-participant observations of meetings regarding & & 15 \\
the business model & & \\
Documents & & \\
Strategy, business model, performance measurement, & & \\
and general company documents & & \\
\end{tabular}


Table 2: Schemas, their sources, and their change regarding the development and use of the company's business model

$\begin{array}{lll}\text { Schemas } \quad \text { Business model development } \quad \text { Business model use } & \begin{array}{l}\text { Types of schema } \\ \text { change observed }\end{array}\end{array}$

\begin{tabular}{|c|c|c|c|}
\hline $\begin{array}{l}\text { Parent schema } \\
\text { (source) }\end{array}$ & $\begin{array}{l}\text { - Clear depiction of vision } \\
\text { (company's vision) }\end{array}$ & $\begin{array}{l}\text { - Clear depiction of vision } \\
\text { (company's vision) } \\
\text { - Better performance measurement } \\
\text { (company's performance } \\
\text { measurement system) }\end{array}$ & Schema addition \\
\hline $\begin{array}{l}\text { Child schema - part A } \\
\text { (source) }\end{array}$ & $\begin{array}{l}\text { - Gain efficiency } \\
\text { (company's strategic priority) }\end{array}$ & $\begin{array}{l}\text { - Maintain efficiency } \\
\text { (lack of opportunities to gain } \\
\text { efficiency) }\end{array}$ & Schema refinement \\
\hline $\begin{array}{l}\text { Child schema - part B } \\
\text { (source) }\end{array}$ & $\begin{array}{l}\text { - Follow asset management plan } \\
\text { (asset management plan document) }\end{array}$ & $\begin{array}{l}\text { - Follow asset management plan } \\
\text { (asset management plan document) }\end{array}$ & Schema sustainment \\
\hline $\begin{array}{l}\text { Child schema - part C } \\
\text { (source) }\end{array}$ & $\begin{array}{l}\text { - Request-for-proposals from clients } \\
\text { (request-for-proposal documents) }\end{array}$ & $\begin{array}{l}\text { - Slow market growth } \\
\text { (market information) }\end{array}$ & Schema replacement \\
\hline
\end{tabular}


Figure 1: ElectricNZ's business model (adapted from company documents and interviews)

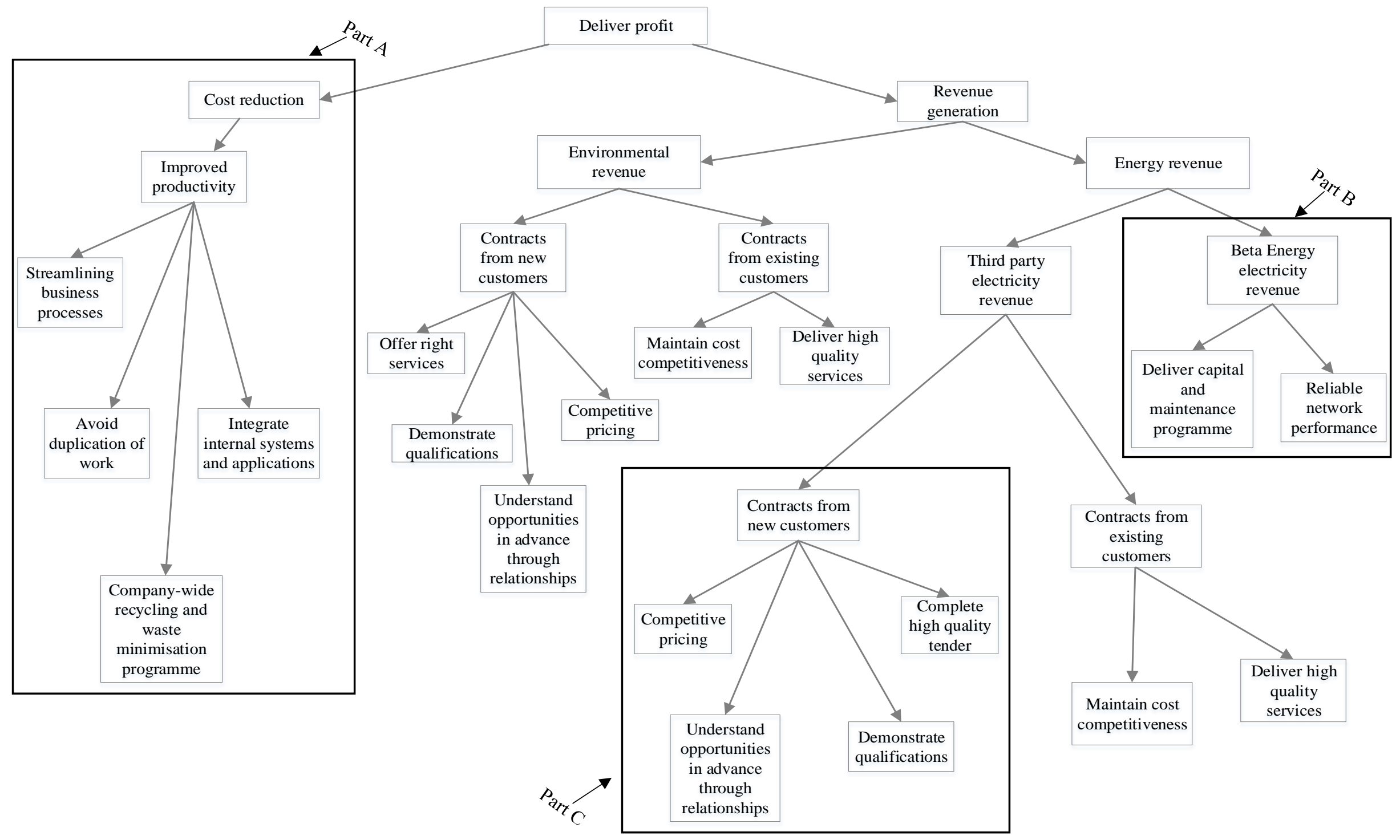


Figure 2: A model of the managerial sensemaking process around business model development and use

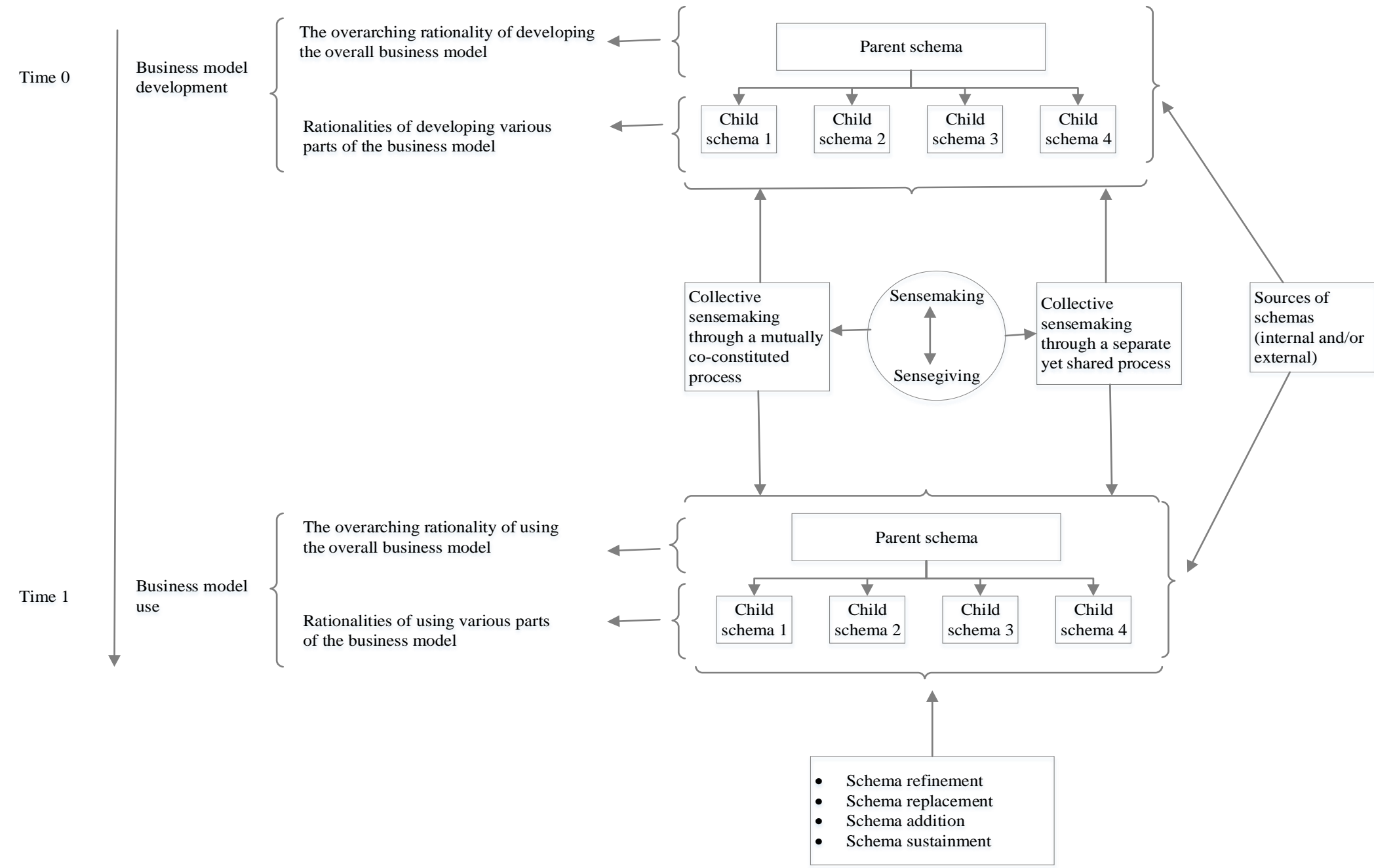

